[Agr. Biol. Chem., Vol. 32, No. 7, p. 851 854, 1968]

\title{
Studies on Oxygen Transfer in Submerged Fermentations
}

\author{
Part VIII. The Effects of Carbon Dioxide and Agitation \\ on Product Formation in Glutamic Acid Fermentation \\ under Controlled Pressure of Dissolved Oxygen*
}

\author{
By Yoshio Hirose, Hiroshi Sonoda, Kazumoto Kinoshita \\ and Hiroshi OKaDA
}

Central Research Laboratories of Ajinomoto Co., Inc., Kawasaki, Japan

Received November 30, 1967

\begin{abstract}
In conventional shaken culture system, control of oxygen supply is performed by changing liquid volume in flasks and it necessarily introduces variation in the effectiveness of agitation and in the partial pressure of carbon dioxide. In jar or tank culture system, also, the changes in mechanical agitation and in the flow rate of air for control of aeration induce similar problems. It is impossible, therefore, to isolate the effects of oxygen on microbial metabolism from these accompanying ones. Hence, there is a basic requirement of making clear distinction among them, and in this paper the effects of agitation and carbon dioxide on product formation are presented in glutamic acid fermentation using the apparatus of controlling the level of dissolved oxygen throughout the fermentation.
\end{abstract}

In the previous papers of the effects of oxygen on various features in glutamic acid fermentation, ${ }^{1,21}$ control of oxygen supply was performed by changing liquid volume in flasks, by selecting suitable cotton plugs with different diffusibility of oxygen and by purging the gas-phase inside the flasks with gas mixtures of different partial pressure of oxygen. The last method could control the oxygen level independently and was employed commonly in the previous works. The other two methods inevitably caused the changes in the effectiveness of agitation and in the partial pressure of carbon dioxide. In conventional jar and tank culture systems, the changes in mechanical agitation and the flow

* This paper was presented at a Meeting of Symposium on Amino Acid and Nucleic Acid held at Sendai, Japan, on 2 October, 1967.

1) Y. Hirose, H. Sonoda, K. Kinoshita and $H$. Okada, Agr. Biol. Chem., 3o, 585 (1966).

2) Y. Hirose, H. Sonoda, K. Kinoshita and H. Okada, ibid., 31, 1210 (1967). rate of air for control of aeration induce similar problems. Clear-cut information was not obtained when these factors were dependent each other, and there was still a basic requirement of making clear distinction between oxygen and these accompanying effects on microbial metabolism. This requirement was attained by employing the system of the automatic control of dissolved oxygen, ${ }^{31}$ in which the effectiveness of oxygen supply was strictly controlled independent of the factors of agitation and carbon dioxide. This paper refers to the clarification of the effects of agitation and carbon dioxide on various features in glutamic acid fermentation under controlled pressure of dissolved oxygen.

\section{EXPERIMENAL METHODS}

Microorganism employed was Brevibacterium lactofermentum. Culture methods were described in the

3) S. D. Siegell and E. L. Gaden, Biotech. and Bioeng., 4, 345 (1962). 
previous paper.1,2) To adjust oxygen supply, the system of controlling dissolved oxygen with electrolytic oxygen 4 ! was used as well as the methods to change liquid volume or oxygen diffusibility of cotton plugs, and of purging the gas-phase inside the flasks with sterile gas of different partial pressure of oxygen.

The concentration of carbon dioxide in the gasphase of the flask was determined by Orsat's gas analysis technique, and controlled by selecting suitable carbon dioxide absorbents such as potassium hydroxide solution or diethanolamine, ${ }^{51}$ or by liberating intermittently $x$ part of carbon dioxide from the flask.

The effectiveness of agitation was controlled by the change of a liquid volume in the flask, or by inserting baffle plates of $2 \mathrm{~cm}$ width and $5 \mathrm{~cm}$ height. The oxygen absorption coefficient, $\mathrm{Kd}$ (mole/ml.min -atm) in both sulfite solution and fermentation broth was used as a measure of the agitation effect.

The oxygen transfer coefficient of a cotton plug, $k$ (mole/min.atm), the oxygen absorption coefficient, $\mathrm{Kd}$ and the rate of oxygen demand (mole/ml.min) were determined by the method of unsteady-state gas analysis' or by the electrolytic method.4) Sulfite oxidation was performed with the reaction mixture of K. Yamada et al. ${ }^{7}$

The other analytical methods were the same as already reported. $1,2,4,81$

\section{EXPERIMENTAL RESULTS}

\section{I) Effects of carbon dioxide on product formation} in glutamic acid fermentation

Table I shows the concentrations of carbon dioxide in gas-phase of flasks under various conditions of operation. It is evident from this table that control of oxygen levels by changing liquid volume of flasks or oxygen diffusibility of cotton plugs inevitably caused the change in the concentration of carbon dioxide. The effects of carbon dioxide on product formation in glutamic acid fermentation are shown in Fig. 1. Fermentation was

4) Y. Hirose, H. Sonoda, K. Kinoshita and H. Okada, Agr. Biol. Chem., 31, 1217 (1967).

5) H. A. Krebs, Biochem. J., 48, 349 (1951).

6) $Y$. Hirose, H. Sonoda, K. Kinoshita and $H$. Okada, Agr. Biol. Chem., 30, 49 (1966).

7) K. Yamada, J. Takahashi and H. Okada, Nippon Nogeikagaku Kaishi, 27, 703 (1953).
TABLE I. $\mathrm{CO}_{2}$ CONCENTRATION UNDER VARIOUS OPERATION CONDITIONS

\begin{tabular}{|c|c|c|}
\hline$\frac{k}{\mathrm{~mol} / \mathrm{min} \cdot \mathrm{atm}}$ & $\begin{array}{c}\text { liquid volume } \\
\mathrm{ml}\end{array}$ & $\mathrm{CO}_{2}$ in $\underset{\%}{\text { gas-phase }}$ \\
\hline $3.7 \times 10^{-4}$ & $\left\{\begin{array}{l}20 \\
40 \\
80\end{array}\right.$ & $\begin{array}{r}5 \sim 6 \\
8 \sim 9 \\
11 \sim 12\end{array}$ \\
\hline $0.8 \times 10^{-4}$ & 20 & $12 \sim 13$ \\
\hline $0.26 \times 10^{-4}$ & 20 & $17 \sim 18$ \\
\hline
\end{tabular}
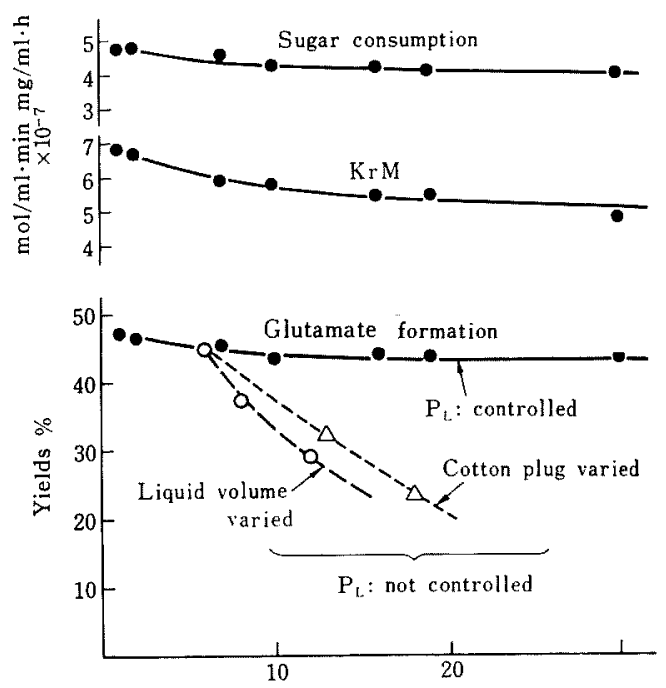

$\% \mathrm{CO}_{2}$ in gas-phase of flask

FrG. 1. Effects of $\mathrm{CO}_{2}$ Concentration on Glutamic Acid Fermentation.

performed in the following three ways of controlled oxygen levels; the first was by changing liquid volume (--O--), the second was by altering the oxygen diffusibility of cotton plugs $\left(-\cdots \triangle^{-\cdots}\right)$ and the third was by controlling the pressure of dissolved oxygen at $0.21 \mathrm{~atm}$ with an operating volume of 80 $\mathrm{ml}$, where the concentration of carbon dioxide was artificially varied (--) In the third method, constant levels of oxygen supply and agitation intensity were attained throughout the fermentation and only the concentration of carbon dioxide was changed, therefore, the effects of carbon dioxide was discussed independently of the other factors.

Although increase of the concentration of 
carbon dioxide was shown to yield decrease in glutamate formation, sugar consumption and respiratory activity, the extent of the decrease at controlled pressure of dissolved oxygen was far less than that observed in the cultivation by the other two ways in which the rate of oxygen supply was varied. This fact implies that the effects of carbon dioxide on product formation was much smaller than those of oxygen.

II) Effects of agitation on product formation in glutamic acid fermentation

To measure the agitation intensity in the shaken cultures, the method of R.P. Rhodes and E. L. Gaden ${ }^{8)}$ was found not to be suitable distinguishing no significant difference in various conditions of operation. On the other hand, oxygen absorption coefficient, $\mathrm{Kd}(\mathrm{mole} / \mathrm{ml} \cdot \mathrm{min} \cdot \mathrm{atm})$ in both sulfite solution and fermentation broth was proved to be a measure of the agitation effect. This interpretation of $\mathrm{Kd}$ has been already approved. ${ }^{9 \prime}$

The effectiveness of shaking (agitation) in several operation conditions is shown in Table II. The variation of liquid volume in flasks led to the change in the effectiveness of agitation as well as in the level of oxygen pressure. Insertion of baffle plates to the liquid part in the flask, however, did not show any substantial effects on the intensity

TABLE II. SHaKing EFFEcts in Various OPERATION CONDITIONS

$\begin{array}{cccc}\begin{array}{c}\text { Liquid } \\ \text { volume } \mathrm{ml}\end{array} & \begin{array}{c}\text { Number of } \\ \text { baffles }\end{array} & \mathrm{Kd} \times \overbrace{10^{-6} \mathrm{~mol} / \mathrm{ml} \cdot \mathrm{min} \mathrm{atm}}^{\text {sulfite }} & \text { biological } \\ 20 & 0 & 7.2 & 5.6 \\ 30 & 0 & 6.0 & - \\ 40 & 0 & 5.3 & 5.4 \\ 60 & 0 & 4.3 & 4.6 \\ & 0 & 3.4 & 4.7 \\ 80 & \left\{\begin{array}{l}0 \\ 1\end{array}\right. & 2.9 & 4.2 \\ 2 & 3.3 & 4.6 \\ 3 & 2.5 & 4.6\end{array}$

8) R. P. Rhodes and E. L. Gaden, Ind. Eng. Chem., 49, 1233 (1957).

9) K. Yamada, T. Yano, J. Takahashi and $M$. Ooki, Nippon Nogeikagaku Kaishi, 30, 501 (1956).

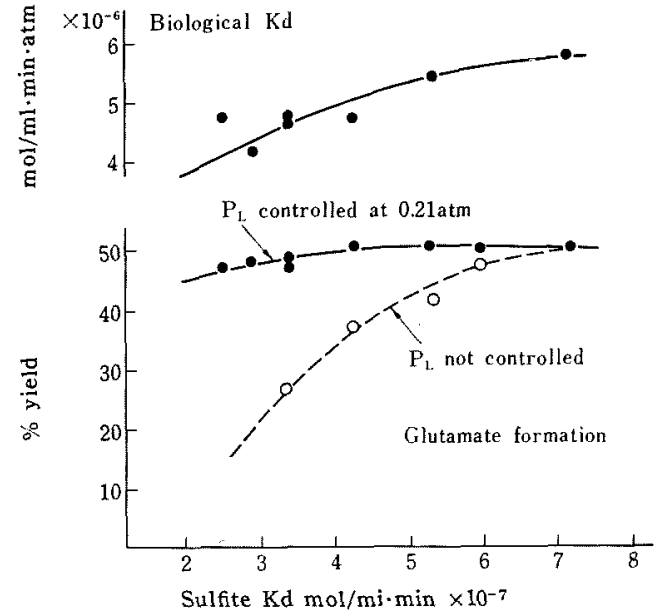

FIG. 2. Effects of Shaking in Glutamic Acid Fermentation.

of agitation. This was coincident with a macroscopic observation of turbulence in the flask. In biological systems, the variation of $\mathrm{Kd}$ was in less extent than that expected from the data in sulfite solution. ${ }^{101}$

Figure 2 shows the effects of agitation on product formation in glutamic acid fermentation under controlled and not controlled pressure of dissolved oxygen. The control of dissolved oxygen was performed at $0.21 \mathrm{~atm}$ under the condition of less than $1 \%$ of carbon dioxide. In this way of the culture, constant levels of oxgen and carbon dioxide were attained, thus the effects of agitation on product formation was examined independently of carbon dioxide and oxygen.

In the culture at strictly controlled level of dissolved oxygen, changes in the effectiveness of agitation hardly affected the formation of glutamate showing remarkable contrast to the culture in which dissolved oxygen was not controlled and oxygen supply was varied. This fact shows the effects of agitation on product formation was not significant in comparison with those of oxygen.

10) Y. Hirose, S. Yamanaka, H. Okada and K. Kinoshita, Agr. Biol. Chem., 29, 989 (1965). 


\section{DISCUSSIONS}

Using the apparatus of controlling dissolved oxygen level with electrolytic oxygen, the effects of carbon dioxide and agitation on metabolic activities of cells were discussed separately one from the others.

The disadvantageous effects of carbon dioxide on microbial metabolism have already been demonstrated in some cases. ${ }^{11 \sim 14} \mathrm{~L}$. Nyiri and Z. L. Lengye ${ }^{14)}$ assumed that aeration was necessary for the biosynthetic process in aerobic microorganisms in two ways; (1) to maintain the oxygen level above the critical level, and (2) to assure ventilation, by which carbon dioxide remained below its inhibitory critical value.

On the other hand, there are numerous publications dealing with the interaction of agitation and aeration in biosynthetic processes, but S. D. Siegell and E. L. Gaden ${ }^{3 !}$ pointed out the necessity of study on agitation effects being independent of aeration. The intention of the present paper was to clarify

11) J. W. Richards, Progress in Ind. Microbiol., 3, 141 (1961).

12) N.S. Golding, J. Dairy Sci., 23, 891 (1940).

13) J. B. Foster and J. B. Davis, Arch. Biochem. 21, 135 (1949).

14) L. Nyiri and Z. L. Lengyel, Biotech. and Bioeng., 7, 343 (1965). the effects of oxygen, carbon dioxide and agitation on product formation, independently of each other, in glutamic acid fermentation. The evidence obtained here indicated that, in this fermentation, some influences of agitation and carbon dioxide on the formation of glutamate were observed, and that their extent was insignificant in comparison with effects of oxygen supply, especially in conventional operation of shaking cultures (Table I and Table II).

On the basis of these data, it seemed reasonable to assume that the methods of controlling oxygen supply by varying liquid volume or diffusibility of cotton plugs were practically independent of agitation and carbon dioxide. In the aeration-agitation studies for scale-up or process design in glutamic acid fermentation, therefore, it was suggested to consider oxygen transfer as the most important factor, paying attention to the accompanying effects such as agitation and carbon dioxide.

Acknowledgement. The authors wish to express their sincere thanks to Dr. Kôichi Yamada, Professor of the University of Tokyo, for his continuing guidance and encouragement. 